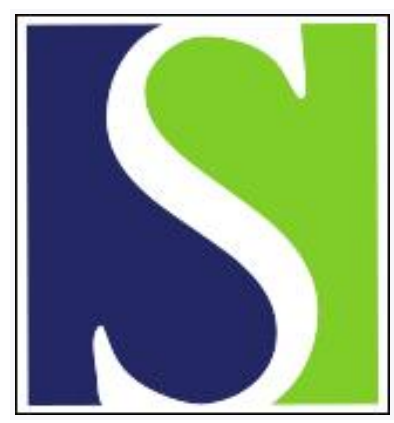

Scand J Work Environ Health 2014;40(4):335-342

https://doi.org/10.5271/sjweh.3413

Published online: 02 Jan 2014, Issue date: 01 Jul 2014

Heavy work and disability pension - a long term follow-up of Swedish construction workers

by Järvholm B, Stattin M, Robroek SJW, Janlert U, Karlsson B, Burdorf A

For workers in a heavy job like construction work, occupational factors are of great importance for disability pension. The majority of years lost are caused by pensions granted at ages 50 years and older. Measures to decrease disability pension should be initiated at earlier stages of work life to decrease effects of negative exposures and increase employability.

Affiliation: Department of Public Health and Clinical Medicine, Umeå University, 90187 Umeå, Sweden. bengt.jarvholm@envmed.umu.se

The following articles refer to this text: 2014;40(4):331-333; 2017;43(5):405-414; 2020;46(1):77-84

Key terms: attributable risk; construction; construction worker; disability pension; employability; epidemiology; heavy work; insurance medicine; public health; Sweden

This article in PubMed: www.ncbi.nlm.nih.gov/pubmed/24385007 


\title{
Heavy work and disability pension - a long term follow-up of Swedish construction workers
}

\author{
by Bengt Järvholm, MD, PhD, ${ }^{1}$ Mikael Stattin, PhD, ${ }^{2}$ Suzan JW Robroek, PhD, ${ }^{3}$ Urban Janlert, MD, PhD, ${ }^{1}$ \\ Bernt Karlsson, MD, PhD, ${ }^{1}$ Alex Burdorf, PhD ${ }^{3}$
}

\begin{abstract}
Järvholm B, Stattin M, Robroek SJW, Janlert U, Karlsson B, Burdorf A. Heavy work and disability pension - a long term follow-up of Swedish construction workers. Scand J Work Environ Health. 2014;40(4):335-342. doi:10.5271/ sjweh.3413
\end{abstract}

Objectives The objective of this study was to investigate the occurrence of disability pensions over time among workers with physically demanding jobs.

Methods The occurrence of disability pension was prospectively studied between 1980-2008 among 325549 Swedish construction workers. The risks for disability pension and years lost of working life were compared among 22 occupational groups, adjusting for age, body mass index, height, and smoking habits.

Results The risk varied considerably among blue-collar workers. For example, rock workers had double the risk of disability pension [relative risk (RR) 2.16, 95\% confidence interval (95\% CI) 1.96-2.39] compared to electricians. Most working years lost due to disability pensions (about $75 \%$ ) were found among men $>50$ years, mainly as a result of musculoskeletal and cardiovascular diseases. The years of working life lost due to disability pension varied from 0.7 (salaried employees) to 3.2 years (rock workers) among occupational groups.

Conclusion Work environment is an important predictor for disability pension among construction workers with those in physically heavy jobs having the highest burden of disability. If the purpose is to increase labor force participation for workers with heavy jobs, strategies to reduce physical demands at work among elderly workers are important.

Key terms attributable risk; employability; epidemiology; insurance medicine; public health; Sweden.

Extending working life has become an important societal challenge, and there is a considerable debate how workers can maintain their work ability as they get older (1-3). The work environment is important as physical and psychosocial demands in certain industries and jobs can make it hard to work with chronic diseases and illhealth. Disability pension is an important means to leave working life. In a European study of 4923 older persons, self-reported physical and psychosocial demands led to an increased exit from paid employment due to work disability during a 4-year follow-up (4). A Finnish study among employees in the public sector reported that job strain was associated with a 1.5-2.4 times higher risk of disability benefit due to musculoskeletal disorders during the 4.6-year follow-up (5). In a study of Swedish construction workers, both physical factors in the work environment and work-related psychosocial factors were associated with an about doubled risk for disability pension during a 20-year follow-up (6).

A better knowledge of the interplay between job demands and ill-health during the life course of the worker is important in order to understand how to prolong labor force participation among workers with heavy jobs. This requires studies with long follow-up periods whereby relevant time windows between demands in the job, types of ill-health, and occurrence of disability benefits can be established. It is also of interest for preventive measures against work-related disability to know if the majority of working years are lost by a limited number of rather young persons or many older

1 Department of Public Health and Clinical Medicine, Umeå University, Umeå, Sweden.

2 Department of Sociology, Umeå University, Umeå, Sweden.

3 Department of Public Health, Erasmus MC, Rotterdam, The Netherlands.

Correspondence to: Bengt Järvholm, Department of Public Health and Clinical Medicine, Umeå University, 90187 Umeå, Sweden. [E-mail: bengt.jarvholm@envmed.umu.se] 
persons who leave working life a few years before eligibility for old age retirement. In the first situation, measures to find and try to increase the work ability of susceptible individuals may be the preferred solution (selective prevention), while in the latter case measures directed at the work environment may have a higher priority (universal prevention). Furthermore, knowledge of the interplay between ill-health and physically heavy demands during working life makes it easier to understand the consequences of an increased statutory retirement age for workers in such jobs.

We have studied disability pension in a large cohort of Swedish construction workers with a follow-up period of $>30$ years. Although modern equipment may have decreased the physical forces needed on the job, pressure on time and productivity may have increased physical as well as psychological demands at work during the past decades. Many jobs in the construction industry are still physically demanding. The construction site is a temporary workplace, meaning that material and tools may have to be carried and the demands may vary (eg, between renovation and the production of new buildings). Construction work also requires climbing on ladders and sometimes working in awkward postures. The aim of this study was to investigate how physically demanding jobs influence the occurrence of disability pensions over time among workers.

\section{Methods}

\section{Study population and design}

According to an agreement between employers and unions, Swedish construction workers were affiliated with the national occupational health service (Bygghälsan) from the mid-1960s until 1 January 1993. All workers were offered free health examinations on a regular basis, and it is estimated that the cumulative participation in health examinations among workers in the Swedish construction industry was about $80 \%$ (6). From 1971, the examination results were stored in a data register. This historical cohort includes 389132 individuals employed in the construction industry, who participated in $\geq 1$ health examination between 1971 and January 1993. The current study was restricted to men, since the proportion of women was small (5.0\%) and consisted primarily of office workers. The following were also excluded: persons with an unknown body mass index (BMI) $(\mathrm{N}=7454)$ and men who were examined before reaching 15 years of age $(\mathrm{N}=1)$ or after 65 years of age $(\mathrm{N}=1725)$. Workers may be transferred to less demanding jobs due to illness. Men with job titles indicating that the worker in this industry had been transferred due to illness (cleaning, stock-room work or transport work) were excluded to decrease the risk of health selection bias ( $\mathrm{N}=6693$ ). Moreover, the retirement age was changed from 67 to 65 years in 1976. Therefore, we restricted all analysis to 1980 or later. Men who were born in 1915 or earlier ( $\mathrm{N}=22799)$, had died $(\mathrm{N}=4473)$, emigrated $(\mathrm{N}=2274)$, or had disability pension $(\mathrm{N}=9835)$ before 1980 were excluded. Persons on full disability pension before they were examined the first time were also excluded ( $\mathrm{N}=109)$. The analysis included 325549 men in total.

Information on job, year of birth, weight, height, BMI, and smoking was used from the first health examination. Until 1985 there were 215 job titles, and in 1985 the classification of jobs was changed to 90 job titles, which could be merged into the 22 occupational groups as provided by technical experts of the industry. The groups were used to assign blue-collar workers to either unskilled or partly skilled manual labor or to skilled manual labor (see table A in appendix). The latter category implied at least 2-3 years of vocational education and apprenticeship including groups such as painters, plumbers, or electricians. The former included groups such as roofers, drivers, and asphalt workers.

The Regional Ethical Review Board provided ethical approval for the study (2011-367-32M).

\section{Disability pension}

Disability pension is a social security benefit given to working age people who have limitations in their working capacity due to ill-health. The Social Insurance Office in Sweden takes all decisions regarding disability pension, and during the past ten years the annual inflow in the program has decreased mainly due to increasingly narrow and tightened eligibility rules. In relation to our study, these changes did not pose a problem since the same institutional rules and regulations apply to all subjects included in the study. However, it may very well be reflected in the incidence of disability pension over time. It is also important to note that, in 2001, Sweden launched a comprehensive old age pension reform that abandoned the fixed pension age of 65 . The statutory retirement age was replaced with an age-related interval (61-67) during which it is possible to draw old age pension. This indeed may affect the overall inflow in the disability pension program but the mean age of old age pension in the total population has only changed slightly between 2001-2011, from 64.8-64.6 years among men (7).

The date of disability pension decisions in the construction worker cohort was available from a linkage with the register of disability pension in the Swedish Social Insurance Office. The legislation for disability pension was changed in 2008 making eligibility for a disability pension much more restrictive. Therefore, 
all our analyses are from 1 January 1980 through 31 December 2008. It is possible to have to $25,50,75$, and $100 \%$ disability pension in Sweden, and the return-towork rate for disability pension recipients is typically very low. The date of disability pension in our analysis was the date the person first received full $(100 \%)$ pension. The register of disability pension includes primary and secondary diagnoses classified according to ICD 9 or ICD 10. In the analysis, we have used the primary diagnosis. We categorized the diagnosis as musculoskeletal (ICD 9: 710-739, ICD 10: M00-M99), cardiovascular (ICD 9: 390-459, ICD 10: I00-I99), psychiatric (ICD 9: 290-319, ICD 10: F00-F99), respiratory (ICD 9: 460-519, ICD 10:J00-J99), neurological (ICD 9: 320.359, ICD 10: G00-G99), injuries (ICD 9: 800-959, ICD 10: S00-S99 T00-T32), or other.

BMI $\left(\mathrm{kg} / \mathrm{m}^{2}\right)$ was calculated from measured weight and height at the first examination. Smoking habits were divided into non-smokers $(41 \%)$, ex-smokers $(15 \%)$, current smokers $(38 \%)$, and unknown smoking habits $(6 \%)$ according to the first examination, and, if no information was available, data from the second or third examination was used.

\section{Statistical analysis}

The year of death or year of emigration was collected through linkage with official registers using the unique personal number of each individual.

Working-years lost were determined by first calculating the proportion of persons on disability pension under observation at a specific age (eg, 58 years) and then summarizing the proportions over all studied ages up to 65 years. In the analysis of years lost according to occupational group, we restricted the analysis to ages $>30$ years, as there were very few cases of workers receiving a disability pension at $<30$ years.

Person-years were calculated from the year after the health examination until censoring due to full-time pension, death, emigration, or 31 December 2008. Regression analysis with a negative binomial distribution was used to calculate relative risk (RR) adjusting for potential confounders as a Poisson regression analysis indicated some over-dispersion. Furthermore, the relations between personal and lifestyle factors and disability pension were estimated. SAS statistical program version 9.3 (SAS Institute, Cary, NC, USA) was applied when RR and their 95\% confidence intervals (95\% CI) were estimated.

As one of the largest occupational groups, electricians were used as a reference category in the analysis. It is a manual job and includes some formal training. This job in the construction industry requires less heavy lifting than some other jobs and probably offers larger possibilities for transfer to less heavy jobs in case of illness.

\section{Results}

There were in total 60373 cases of disability pension between 1980-2008. The number of disability pensions varied over the years with a peak in 1993 (figure 1). On average, $18.5 \%$ of the men in the cohort received a disability pension (table 1).

Disability pension was strongly dependent on age: age group 20-29 years: 44 cases, 30-39 years: 1245 cases, 40-49 years: 5694 cases, 50-59 years: 24197 cases, and 60-64 years: 29193 cases. The proportion of psychiatric diagnoses was highest in the youngest group (61\%, 27 cases among men 20-29 years) and lowest in the oldest age group $(4 \%, 1089$ cases among men 60-64 years) (figure 2). The proportions of diagnoses in musculoskeletal disorders and cardiovascular diseases were similar over time in the age-groups 50-59 and 60-64 years (figure 3 ). The proportion of psychiatric diagnoses increased during the 2000 s, from about $3 \%$ to about $7 \%$.

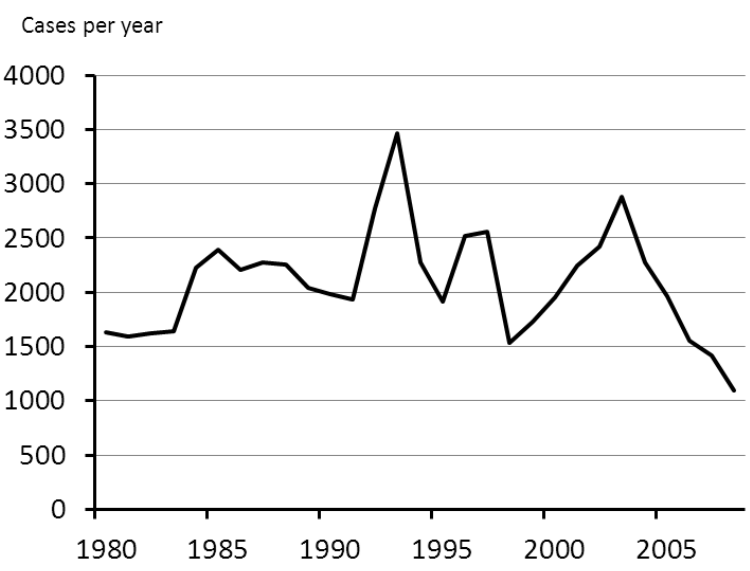

Figure 1. Number of disability pensions per calendar year.

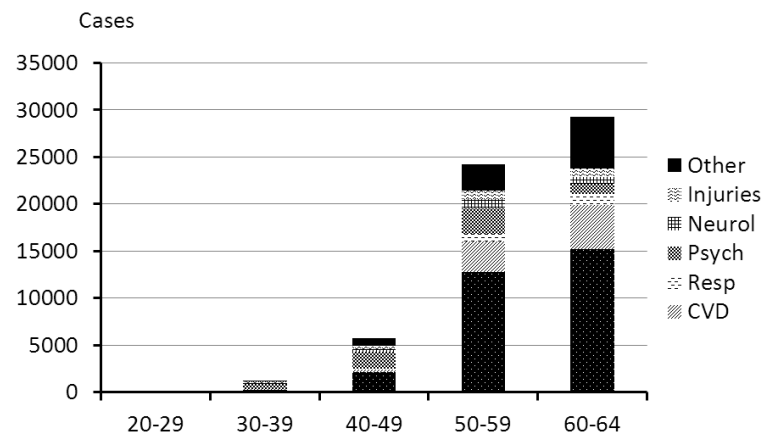

Figure 2. Number of disability pensions depending on age and diagnoses [neurol=neurological; psych=psychiatric; resp=respiratory; CVD=cardiovascular]. 
The RR of disability pension varied between the occupational groups (table 2). Salaried employees and foremen had the lowest risk while rock workers, concrete workers, roofers, and insulators had the highest risks. Apart from age, the RR were also adjusted for smoking habits, BMI, height and calendar period but changed only modestly (table 2). An analysis according to occupational class among the manual workers (excluding foremen, salaried workers and the job category "others") showed a very weak association (RR $0.98,95 \%$ CI $0.96-1.01$ skilled versus un- or partly skilled).

Table 1. Occupation, year of birth, and proportion with a disability pension (DP) 1980-2008 in a cohort of construction workers in Sweden ( $\mathrm{N}=325$ 549).

\begin{tabular}{|c|c|c|c|}
\hline Occupation & $\mathrm{N}$ & $\begin{array}{l}\text { Year of birth, } \\
\text { mean }\end{array}$ & $\mathrm{DP}(\%)$ \\
\hline Rock workers & 3089 & 1938 & 37.4 \\
\hline Roofers & 1232 & 1949 & 24.1 \\
\hline Insulators & 2647 & 1950 & 21.2 \\
\hline Concrete workers & 27996 & 1942 & 29.8 \\
\hline Earth-moving workers & 10777 & 1945 & 24.5 \\
\hline Painters & 22085 & 1948 & 20.1 \\
\hline Crane operators & 3189 & 1940 & 33.6 \\
\hline Floor-layers & 5059 & 1950 & 18.9 \\
\hline Others & 46909 & 1949 & 17.4 \\
\hline Brick-layers & 9204 & 1944 & 25.3 \\
\hline Sheet-metal workers & 11268 & 1951 & 15.6 \\
\hline Woodworkers & 61985 & 1949 & 17.6 \\
\hline Plumbers and pipe fitters & 23039 & 1947 & 19.7 \\
\hline Repairers & 2596 & 1944 & 21.8 \\
\hline Drivers & 4274 & 1941 & 22.5 \\
\hline Asphalt workers & 3776 & 1945 & 21.8 \\
\hline Glaziers & 2532 & 1950 & 15.6 \\
\hline Machine operators & 10300 & 1944 & 21.2 \\
\hline Refrigeration repairers & 1225 & 1952 & 12.3 \\
\hline Electricians & 34327 & 1952 & 10.2 \\
\hline Foremen & 27359 & 1942 & 12.7 \\
\hline Salaried employees & 10681 & 1940 & 10.8 \\
\hline Total & 325549 & 1946 & 18.5 \\
\hline
\end{tabular}

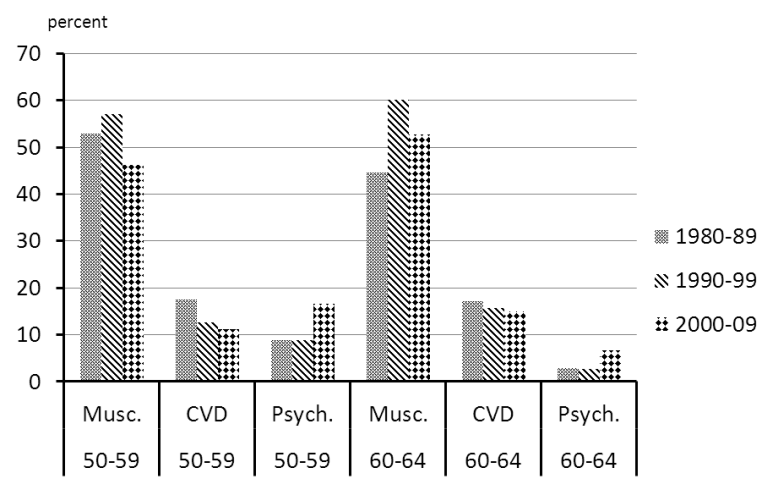

Figure 3. Frequency of diagnosis according to time period among men 50-59 and 60-64 years, respectively [musc=musculoskeletal, $\mathrm{cvd}=$ cardiovascular; psych=psychiatric $]$.

The number of years lost in working life due to disability pension varied between $0.7-3.2$ years. The majority of years lost were among men who received disability pension at $\geq 50$ years (ie, about $75 \%$, table $3)$. Even if the years lost are much larger among an individual who is $30-40$ years at the time of disability retirement, the overall loss of working years in this age group is small compared to those $>50$ years. It is of interest to note that the largest absolute differences in relative contribution to total working years lost were found in the age groups $40-49(8.1-29.4 \%)$ and $50-59$ $(35.5-57.7 \%)$ years.

\section{Discussion}

This large prospective study shows that construction workers have a substantial loss of working life due to disability pension, and the risk of becoming disabled varied according to occupation among blue-collar workers in the same industry. Occupational class and education are strong predictors of disability pension comparing, for example, professionals with blue-collar workers $(8,9)$. Most of the men in this study were manual workers with similar educational background. They have similar access to healthcare and are depen-

Table 2. Relative risks (RR) of disability pension before age 65 according to occupational groups in the construction industry (electricians=reference group). [ $95 \% \mathrm{Cl}=95 \%$ confidence interval]

\begin{tabular}{lcccc}
\hline Occupational group & $\mathrm{RR}{ }^{\mathrm{a}}$ & $95 \% \mathrm{Cl}$ & $\mathrm{RR}{ }^{\mathrm{b}}$ & $95 \% \mathrm{Cl}$ \\
\hline Rock workers & 2.34 & $2.09-2.63$ & 2.16 & $1.96-2.39$ \\
Concrete workers & 2.11 & $1.94-2.30$ & 1.94 & $1.81-2.09$ \\
Insulators & 2.00 & $1.75-2.28$ & 1.90 & $1.69-2.14$ \\
Roofers & 2.02 & $1.72-2.38$ & 1.88 & $1.62-2.17$ \\
Earth-moving workers & 1.88 & $1.71-2.08$ & 1.75 & $1.61-1.90$ \\
Painters & 1.98 & $1.81-2.16$ & 1.88 & $1.75-2.03$ \\
Brick-layers & 1.86 & $1.68-2.05$ & 1.77 & $1.63-1.93$ \\
Others & 1.92 & $1.77-2.09$ & 1.74 & $1.63-1.87$ \\
Crane operators & 1.89 & $1.68-2.12$ & 1.71 & $1.55-1.88$ \\
Floor-layers & 1.74 & $1.55-1.95$ & 1.71 & $1.55-1.89$ \\
Woodworkers & 1.59 & $1.46-1.73$ & 1.53 & $1.43-1.63$ \\
Sheet-metal & 1.58 & $1.42-1.75$ & 1.50 & $1.38-1.64$ \\
workers & & & & \\
Plumbers and & 1.49 & $1.36-1.64$ & 1.41 & $1.30-1.52$ \\
pipe fitters & & & & \\
Repairers & 1.49 & $1.30-1.70$ & 1.39 & $1.23-1.57$ \\
Asphalt workers & 1.41 & $1.25-1.60$ & 1.34 & $1.20-1.49$ \\
Glaziers & 1.34 & $1.15-1.55$ & 1.29 & $1.13-1.48$ \\
Drivers & 1.38 & $1.23-1.56$ & 1.26 & $1.14-1.40$ \\
Refrigeration repairers & 1.24 & $1.01-1.52$ & 1.24 & $1.03-1.50$ \\
Machine operators & 1.27 & $1.15-1.41$ & 1.17 & $1.07-1.27$ \\
Electricians & 1.00 & & 1.00 & \\
Foremen & 0.66 & $0.60-0.73$ & 0.65 & $0.60-0.70$ \\
Salaried employees & 0.54 & $0.48-0.61$ & 0.54 & $0.48-0.59$ \\
\hline a Adjusted for age. & & & & \\
${ }^{b}$ Adjusted for age, calendar period, BMI, height, smoking habits. &
\end{tabular}


dent on similar economic business cycles. Therefore, it is reasonable to attribute the differences in risks between the occupational groups among blue-collar workers primarily to differences in working conditions. This may be caused by impaired health due to occupational risk factors, but also an effect of the fact that strenuous jobs in the construction industry hamper workers with chronic diseases to remain productive at work. Self-reported heavy physical job has been found to be a predictor of disability pension in other studies $(8,10)$.

The results of this study might underestimate the effect of heavy physical work demands on disability pension. Occupational title is the primary determinant in this study with a long follow-up, and this may be influenced by ill-health as the selection process (ie, the workers in heavy jobs may be more fit than those in less physically demanding jobs) would underestimate the risk. Furthermore, before a person is granted a disability pension, they mostly have had substantial periods of sick leave. There is also a possibility of part-time

Table 3. Percent of years lost due to disability pension (DP) according to age at DP among construction workers in Sweden.

\begin{tabular}{|c|c|c|c|c|c|}
\hline \multirow{3}{*}{$\begin{array}{l}\text { Occupational } \\
\text { group }\end{array}$} & \multirow{3}{*}{$\begin{array}{c}\text { Total } \\
\text { years } \\
\text { lost }\end{array}$} & \multicolumn{4}{|c|}{ Age at disability pension a } \\
\hline & & $30-39$ & $40-49$ & $50-59$ & $60-64$ \\
\hline & & $\begin{array}{c}\text { Years lost } \\
(\%)\end{array}$ & $\begin{array}{c}\text { Years lost } \\
(\%)\end{array}$ & $\begin{array}{c}\text { Years lost } \\
(\%)\end{array}$ & $\begin{array}{c}\text { Years lost } \\
(\%)\end{array}$ \\
\hline Rock workers & 3.16 & 3.0 & 17.1 & 57.7 & 22.3 \\
\hline Roofers & 3.03 & 6.2 & 14.7 & 57.7 & 21.4 \\
\hline Insulators & 3.02 & 10.0 & 25.5 & 43.0 & 21.6 \\
\hline $\begin{array}{l}\text { Concrete } \\
\text { workers }\end{array}$ & 2.71 & 6.4 & 17.8 & 48.7 & 27.2 \\
\hline $\begin{array}{l}\text { Earth-moving } \\
\text { workers }\end{array}$ & 2.62 & 6.4 & 18.6 & 49.8 & 25.2 \\
\hline Painters & 2.58 & 9.7 & 17.3 & 50.1 & 22.9 \\
\hline $\begin{array}{l}\text { Crane } \\
\text { operators }\end{array}$ & 2.49 & 2.1 & 16.4 & 50.8 & 30.6 \\
\hline Floor-layers & 2.42 & 5.6 & 15.3 & 53.2 & 25.8 \\
\hline Others & 2.40 & 10.0 & 23.7 & 44.2 & 22.1 \\
\hline Brick-layers & 2.37 & 7.8 & 14.1 & 51.4 & 26.7 \\
\hline $\begin{array}{l}\text { Sheet-metal } \\
\text { workers }\end{array}$ & 2.21 & 8.1 & 16.1 & 48.0 & 27.8 \\
\hline Woodworkers & 2.10 & 6.6 & 15.6 & 47.5 & 30.3 \\
\hline $\begin{array}{l}\text { Plumbers and } \\
\text { pipe fitters }\end{array}$ & 2.10 & 6.3 & 15.5 & 47.5 & 30.7 \\
\hline Repairers & 2.10 & 4.4 & 18.4 & 50.3 & 27.0 \\
\hline Drivers & 2.05 & 3.4 & 20.3 & 53.3 & 23.1 \\
\hline $\begin{array}{l}\text { Asphalt } \\
\text { workers }\end{array}$ & 2.04 & 1.9 & 15.7 & 52.4 & 30.1 \\
\hline Glaziers & 2.02 & 9.0 & 29.4 & 35.5 & 26.1 \\
\hline $\begin{array}{l}\text { Machine } \\
\text { operators }\end{array}$ & 1.90 & 2.3 & 17.8 & 53.2 & 26.7 \\
\hline $\begin{array}{l}\text { Refrigeration } \\
\text { repairers }\end{array}$ & 1.78 & 4.5 & 19.3 & 47.4 & 28.8 \\
\hline Electricians & 1.41 & 4.8 & 13.4 & 46.6 & 35.2 \\
\hline Foremen & 0.91 & 3.8 & 8.1 & 49.8 & 38.3 \\
\hline $\begin{array}{l}\text { Salaried } \\
\text { employees }\end{array}$ & 0.74 & 0.1 & 14.4 & 48.9 & 36.7 \\
\hline $\begin{array}{l}\text { All blue collar } \\
\text { workers }\end{array}$ & 2.25 & 6.9 & 17.2 & 48.4 & 27.5 \\
\hline
\end{tabular}

a Only ages 30 years and older considered in the analysis. disability pension in Sweden. Thus, the estimated lost years of work life is an underestimation of total years lost as we have used the age at full disability pension in the analyses.

The variability over the calendar years in the number of cases with new disability pension (figure 1) shows it is not only disease and requirements in the job that influence the rate of disability pension. As stated in the introduction, institutional changes concerning both the disability pension program and the design of the old age retirement system may quite heavily affect annual rates of disability pension beneficiaries. This also applies to the practice and the economic situation of the industry. Such factors are difficult to adjust for in analyses, but the comparison between jobs in this study may not be strongly dependent on such factors as all study subjects were exposed to the same institutional framework and came from the same industry.

The disability pensions were mostly granted to workers $>50$ years. Chronic disorders and diseases are more common with increasing age, and physical fitness decreases with age. Musculoskeletal disorders were the most common diagnosis for cases $>50$ years, and differences in disability pension across occupational groups may depend on how physically demanding the jobs were. Manual workers in this industry have to work in awkward postures and lift and carry heavy material, which may lead to musculoskeletal disorders and other injuries (11). The exposure to such factors may differ between the jobs in this study population. Rock workers mostly work outdoors and have heavy equipment that has to be transported. The need for muscle strength is probably more important for a rock worker than an electrician. Dutch studies have found an increased prevalence of multi-site musculoskeletal system complaints among construction workers $(12,13)$. Both age and cumulative exposure may be of importance. However, a study of carpenters found that the effect of age on the occurrence of musculoskeletal disorders was non-significant when cumulative exposure was included in the analysis (14), indicating that the effect of age on musculoskeletal disorders might be mediated by cumulative exposure.

The findings show that occupational factors that impair health or restrict the possibility to work with illness have great importance for construction workers. A RR of 2, as when comparing rock workers and electricians, would mean that $50 \%$ of disability pension among the former could be attributed to occupational factors if the risk estimates were adjusted for all confounders. The working conditions may exert a direct influence by causing particular diseases but may also have an indirect influence, whereby working conditions influence the possibilities to continue working with a disease in a particular occupational group. A driver with cardio- 
vascular disease may be more productive in his job than an insulator with cardiovascular disease, and possibilities for adjustments of the job are probably better for a driver than an insulator, especially if the latter works in a small firm. Due to the structure of the cohort, without specific information on work and disease collected at fixed periods over time, we were unable to distinguish between these mechanisms.

The large proportion of disability benefits in the oldest age group is similar to the findings in a study of Irish construction workers where $43 \%$ were $\geq 60$ years (15). The construction workers had a considerably higher risk for a disability pension compared to salaried employees (eg, the risk for rock workers was four times higher than for salaried employees, table 2). Our results are also similar to the findings in a Swiss study, where $57 \%$ of construction workers survived in working life until their $65^{\text {th }}$ birthday compared to $89 \%$ for workers in science and related professionals (16). This may not just depend on working conditions but also health. A recent study from the US found that manual construction workers more often had poorer health than white-collar workers (17).

There are several possible confounders in studies of disability pension, the most obvious is age. When smoking, BMI, and height were added, the risks changed modestly (table 2) indicating they were rather modest confounders in this study. The importance of confounders in studies of disability pension may depend on the occupational groups included. Obesity is a well-known predictor of disease [eg, osteoarthritis of the hip and knee (18-20)] and persons with osteoarthritis may have difficulties to stay in a heavy job. We adjusted for height as strength may be an important factor in some heavy jobs and height may be an indicator of strength (21). There are other possible confounders, such as civil status and education, which may explain some of the difference between salaried and blue-collar workers in this cohort, but this is less probable as an explanation for the differences among occupational groups of bluecollar workers.

The results of our study show that when society wants to increase worklife participation among construction workers, a major effort should be directed to enable persons $>50$ years to remain in paid employment for a longer time (table 3 ). In many of the occupational groups, about $80 \%$ of lost years of working life were found among men who retired due to disability at ages $>50$ years. Even if retirement at a young age has a high impact on lost working years, it is probably more beneficial for society to ensure older workers work for longer. In some occupations, such as rock workers and insulators, almost half of the men had a disability pension before the age of 64 years. This means that if the official retirement age is increased by one year, at least half a year of working life is lost during the last year (ie, 65-66 years). Half a year is a considerable proportion of years lost in most occupational groups in the construction industry (table 2). Thus, most measures that increase the possibility to stay in paid employment for workers aged $\geq 60$ will be very profitable for society if the goal is to increase labor force participation. Although measures that decrease the occurrence of disability pension among workers around 30-40 years of age may seem more important on an individual level, they will have only a modest effect on labor supply. The idea that strategies aimed at many persons with a small loss are more beneficial than measures targeted at a few persons with a heavy loss is an example of Rose's prevention paradox (22). Preventive measures for decreasing impairment of health among older workers and measures to improve the possibility to remain in the workforce with chronic diseases will probably also benefit younger workers. Strategies to improve psychosocial job characteristics may improve both the willingness and possibility to work $(6,23)$. A strategy focusing on the men who get disability pension at younger ages needs to address factors associated with psychiatric diseases. Such a strategy will probably have limited importance for increasing labor force participation among construction workers.

Understanding the occupational differences in the risk of disability pension as an effect of long-term exposure to hazardous working conditions also points towards a conclusion in line with a life-course perspective $(24,25)$. Individual capacities to continue working later in life are actually shaped during a long period of work, during which advantages and disadvantages are accumulated. Interventions that seriously seek to improve older workers' capabilities to remain in the workforce should therefore not only target employees when they are older. Rather, such measures should be initiated at earlier stages in the work life in order to influence the overall wear and tear due to cumulative exposures and to improve employability. This in turn requires new human resource strategies and actions that take into consideration such long-term planning.

In conclusion, this study shows that a considerable proportion of the lost years of working life among construction workers are due to disability pension among those aged $>60$ years. Preventive measures to decrease factors causing impaired health and improving the possibilities to continue working with chronic disorders are of paramount importance for construction workers to support and enable them to remain in paid employment, especially beyond the age of 60 years. 


\section{Acknowledgment}

The Swedish Research Council for Health, Working Life and Welfare supported this study (2011-426).

\section{References}

1. Christensen K, Doblhammer G, Rau R, Vaupel JW. Ageing populations: the challenges ahead. Lancet. 2009;374(9696):1196-208. http://dx.doi.org/10.1016/S01406736(09)61460-4

2. Silverstein M. Meeting the challenges of an aging workforce. Am J Ind Med. 2008;51(4):269-80. http://dx.doi.org/10.1002/ ajim. 20569 .

3. Ilmarinen J. Work ability--a comprehensive concept for occupational health research and prevention. Scand J Work Environ Health. 2009;35(1):1-5. http://dx.doi.org/10.5271/ sjweh.1304.

4. Robroek SJ, Schuring M, Croezen S, Stattin M, Burdorf A. Poor health, unhealthy behaviors, and unfavorable work characteristics influence pathways of exit from paid employment among older workers in Europe: a four year follow-up study. Scand J Work Environ Health. 2013;39(2):125-33. http://dx.doi.org/10.5271/sjweh.3319.

5. Mäntyniemi A, Oksanen T, Salo P, Virtanen M, Sjösten N, Pentti J, et al. Job strain and the risk of disability pension due to musculoskeletal disorders, depression or coronary heart disease: a prospective cohort study of 69,842 employees. Occup Environ Med. 2012;69(8):574-81. http://dx.doi. org/10.1136/oemed-2011-100411.

6. Stattin M, Järvholm B. Occupation, work environment, and disability pension: a prospective study of construction workers. Scand J Public Health. 2005;33(2):84-90. http:// dx.doi.org/10.1080/14034940410019208.

7. Karlsson H, Olsson H. Medelpensioneringsålder och utträdesålder 2011. [Mean age of pension and withdrawal age 2011]. Stockholm; 2012.

8. Krause N, Lunch J, Kaplan G, Cohen R, Goldberg DE, Salonen J. Predictors of disability retirement. Scand J Work Environ Health. 1997;23(6):403-13. http://dx.doi.org/10.5271/ sjweh.262.

9. Leinonen T, Pietiläinen $\mathrm{O}$, Laaksonen M, Rahkonen $\mathrm{O}$, Lahelma E, Martikainen P. Occupational social class and disability retirement among municipal employees - the contribution of health behaviors and working conditions. Scand J Work Environ Health. 2011;37(6):464-72. http:// dx.doi.org/10.5271/sjweh.3182.

10. Lahelma E, Laaksonen M, Lallukka T, Martikainen P, Pietiläinen $\mathrm{O}$, Saastamoinen $\mathrm{P}$ et.al. Working conditions as risk facotrs for disability retirement: a longitudinal register linkage study. BMC Public Health 2012;12:309. http://dx.doi. org/10.1186/1471-2458-12-309.

11. Schwatka NV, Butler LM, Rosecrance JR. An aging workforce and injury in the construction industry. Epidemiol Rev. 2012;34(1):156-67. http://dx.doi.org/10.1093/epirev/ mxr020.

12. de Zwart BC, Frings-Dresen MH, van Duivenbooden JC. Senior workers in the Dutch construction industry: a search for agerelated work and health issues. Exp Aging Res. 1999;25(4):38591. http://dx.doi.org/10.1080/036107399243841.

13. Hoonakker P, van Duivenbooden C. Monitoring working conditions and health of older workers in Dutch construction industry. Am J Ind Med. 2010;53(6):641-53. http://dx.doi. org/10.1002/ajim.20838.

14. Lemasters GK, Atterbury MR, Booth-Jones AD, Bhattacharya A, Ollila-Glenn N, Forrester C, et al. Prevalence of work related musculoskeletal disorders in active union carpenters. Occup Environ Med. 1998;55(6):421-7. http://dx.doi. org/10.1136/oem.55.6.421.

15. Brenner $H, A$ Ahern W. Sickness absence and early retirement on health grounds in the construction industry in Ireland. Occup Environ Med. 2000;57(9):615-20. http://dx.doi.org/10.1136/ oem.57.9.615

16. Gubéran E, Usel M. Permanent work incapacity, mortality and survival without work incapacity among occupations and social classes: a cohort study of ageing men in Geneva. Int $\mathrm{J}$ Epidemiol. 1998;27(6):1026-32. http://dx.doi.org/10.1093/ ije/27.6.1026.

17. Dong XS, Wang X, Daw C, Ringen K. Chronic diseases and functional limitations among older construction workers in the United States: a 10-year follow-up study. J Occup Environ Med. 2011;53(4):372-80. http://dx.doi.org/10.1097/ JOM.0b013e3182122286.

18. Järvholm B, Lewold S, Malchau H, Vingård E. Age, bodyweight, smoking habits and the risk of severe osteoarthritis in the hip and knee in men. Eur J Epidemiol. 2005;20(6):537-42. http://dx.doi.org/10.1007/s10654-0054263-x.

19. Järvholm B, From $\mathrm{C}$, Lewold $\mathrm{S}$, Malchau H, Vingård E. Incidence of surgically tre ated osteoarthritis in the hip and knee in male construction workers. Occup Environ Med. 2008;65(4):275-8. http://dx.doi.org/10.1136/ oem.2007.033365.

20. Robroek SJ, Reeuwijk KG, Hillier FC, Bambra CL, van Rijn RM, Burdorf A. The contribution of overweight, obesity, and lack of physical activity to exit from paid employment: a meta-analysis. Scand J Work Environ Health. 2013;39;233-40. http://dx.doi.org/10.5271/sjweh.3354.

21. Hank K, Jurges H, Schupp J, Wagner GG. Isometrische Greifkraft und sozialgerontologische Forschung: Ergebnisse und Analysepotentiale des SHARE und SOEP. [Isometric grip strength and social gerontological research: results and analytic potentials of SHARE and SOEP]. Z Geronotol Geriat. 2009;42:117-126. http://dx.doi.org/10.1007/s00391-008$0537-8$

22. Rose G. The Strategy of Preventive Medicine. Oxford: Oxford University Press; 1992. 
23. Oude Hengel KM, Blatter BM, Geuskens GA, Koppes LL, Bongers PM. Factors associated with the ability and willingness to continue working until the age of 65 in construction workers. Int Arch Occup Environ Health. 2012;85(7):783-90. http:// dx.doi.org/10.1007/s00420-011-0719-3.

24. Elder G. Time, human agency and social-change - perspectives on the life course. Social Psychology Quarterly. 1994;57(1):415. http://dx.doi.org/10.2307/2786971.
25. Dannefer D. Cumulative advantage/disadvantage and the life course: cross-fertilizing age and social science theory. J Gerontol B Psychol Sci Soc Sci. 2003;58(6):S327-37. http:// dx.doi.org/10.1093/geronb/58.6.S327.

Received for publication: 13 May 2013

\section{Appendix}

Table A. Classification of blue-collar workers into skilled and partly or non-skilled

\begin{tabular}{ll}
\hline Skilled & Partly or non-skilled \\
\hline Concrete workers & Rock workers \\
Painters & Roofers \\
Brick-layers & Insulators \\
Sheet-metal workers & Earthmoving workers \\
Woodworkers & Crane operators \\
Plumbers and pipe fitters & Floor-layers \\
Repairers & Drivers \\
Glaziers & Asphalt workers \\
Refrigeration repairers & Machine operators \\
Electricians &
\end{tabular}

